\title{
Volunteerism Among Hospitalists and Non-Hospitalists at Academic and Community Medical Centers in North Carolina
}

\author{
Michael J. Gilchrist ${ }^{1}$, Richard Hobbs ${ }^{1}$, E. Allen Liles ${ }^{1}$ \\ ${ }^{1}$ Division of Hospital Medicine, Department of Medicine, University of North Carolina, Chapel Hill, NC \\ Correspondence: E. Allen Liles (edmund_liles@med.unc.edu)
}

Received December 12, 2016; accepted March 9, 2017

Background: Volunteerism is common in the United States, though less is known about volunteerism among medical professionals. We aimed to record and compare volunteer activities among hospitalists and non-hospitalists in academic and community centers. Methods: We created a structured 18-question survey asking respondents to quantify professional volunteer service within the preceding 12 months. Participants were medical providers at the University of North Carolina Hospitals (academic hospitalists, internists and pediatricians) and hospitalists at four other North Carolina hospitals. Main measures were number of hours spent volunteering in the previous 12 months and types of volunteer activities performed.

Results: There were 101 survey participants. When comparing hospitalists to nonhospitalists, there were no statistically significant differences in the number of hours spent volunteering $(\mathrm{p}=0.112)$. Those who were 34 years old or younger spent fewer hours volunteering than those $35-44$ years old $(\mathrm{p}=0.082)$ or 45 years old or older $(\mathrm{p}=0.074)$. Those with 10 or more years of clinical experience spent significantly more hours volunteering $(\mathrm{p}=0.035)$. Males spent significantly more hours volunteering than females $(\mathrm{p}=0.036)$. Providers with children in the household spent significantly more hours volunteering than those without children $(\mathrm{p}=0.034)$. Providers at academic hospitals spent significantly more hours than those at community hospitals $(\mathrm{p}=0.011)$. Limitations: Data limited by potential recall bias associated with self-report and limited to survey respondents.

Conclusions: Hospitalists and non-hospitalist health professionals volunteer similar amounts. Volunteerism was significantly influenced by age, gender, clinical experience, presence of children in the household, and working in an academic center.

\section{Introduction}

Volunteerism is common in the United States, with $25.4 \%$ of U.S. population reporting some form of volunteering in a 2013 national survey ${ }^{1}$. Volunteerism is associated with a number of improved health outcomes including lower rates of depression ${ }^{2,3}$ and hypertension ${ }^{4}$, and increased longevity ${ }^{5-7}$. In the general population, women, married persons, and those with children volunteer at higher rates ${ }^{1}$. When stratified by age, thirtyfive to 44 year-olds are most likely to volunteer, with volunteering lowest among 20-24 year olds ${ }^{1}$. The majority of volunteer hours are spent with religious organizations, education/youth service organizations, and social or community service organizations ${ }^{1}$. 
Less is known about physician volunteerism. A 2012 Medscape survey reported that two-thirds of physicians participated in some form of volunteer activity in the previous year ${ }^{8}$. Among survey respondents, doing any form of volunteer work was associated with higher levels of happiness. Family physicians who most highly value benevolence and volunteerism have also been reported to be more satisfied in their clinical practice 9 Despite the potential benefits to both community and the individual, physicians are less likely to volunteer than the general public and lawyers ${ }^{10}$. Reported barriers to volunteerism include time, malpractice and liability concerns, language barriers, lack of patient-provider continuity, and perceived lack of resources at volunteer medical facilities ${ }^{11}$.

Hospital medicine is an emerging medical field and knowledge of how often and what type of volunteer activities hospitalist physicians undertake may be helpful to maximize professional development and job satisfaction. Our hospitalist group at the University of North Carolina (UNC), a tertiary academic center, is comprised of physicians certified in internal medicine, pediatrics, and combined internal medicine/pediatrics. The UNC physician staff in internal medicine and pediatrics also includes non-hospitalist physicians in those disciplines. Our medical community also includes several community hospitals with hospital medicine programs. In this report, we describe the frequency and type of professional volunteerism among hospitalists, general internists, and pediatricians practicing at five academic and community medical centers in North Carolina.

\section{Methods}

\section{Survey Participants}

We conducted a cross-sectional study of healthcare providers at five North Carolina hospitals. We included two academic centers, the University of North Carolina Hospitals (UNC) and Duke University Medical Center (DUMC), and three community hospitals WakeMed Hospitals (WMH), Rex Hospital (RH) and Duke Regional Hospital (DRH). Based on previously reported survey work ${ }^{6,9,10}$, we created an 18-item anonymous questionnaire that asked respondents to quantitatively report demographic information and types and frequency of volunteer activities within the past 12 months (see appendix). We defined volunteer activities as those in which the person used his or her skills as a medical professional. The survey was distributed via an Internet polling website (Surveymonkey.com) in July of 2013. No incentives to complete the survey were offered, but all faculty in each department were asked to complete the survey. Respondents were asked to describe their professional volunteer activities. At UNC, survey participants included physicians from hospital medicine, along with nonhospitalist physicians from the Divisions of General Internal Medicine, and General Pediatrics and Adolescent Medicine. Responses from other hospitals were solely from hospitalists.

\section{$\underline{\text { Outcomes }}$}

Measured outcomes included rates and hours of professional (medical student/resident teaching outside of normal working hours, volunteer medical clinics, international/domestic medical trips, medical advocacy, professional group involvement) and non-professional (school, nursing home, youth sports coach, organizational 
fundraising, faith based, political advocacy, food distribution, community groups) volunteerism among survey respondents. We also report the different types of volunteer activities and demographics of survey respondents including years of experience, age and marital and child status.

\section{$\underline{\text { Analysis }}$}

The mean number of reported volunteer hours by demographic characteristics and among hospitalist vs. non-hospitalist internists and pediatricians were tested for differences using student's t tests. Data were analyzed using Predictive Analytics Software (formerly SPSS), version 18.

\section{Results}

One hundred and one physicians completed the survey (70\% response rate from UNC, $19 \%$ from other hospitals). The majority, $62 \%(n=63)$, reported having volunteered in the last 12 months. Fifty-nine percent reported participating in a professional capacity and $60 \%$ in a non-professional capacity within the prior 12 months. Table 1 describes the sample in more detail.

Table 1. Demographics of survey respondents

\begin{tabular}{|l|l|c|c|}
\hline Characteristic & & $\mathbf{n = 1 0 1}$ & \% \\
\hline Age & 34 years or younger & 37 & 36.6 \\
\hline & $35-44$ years & 39 & 38.6 \\
\hline Gender & 45 years or older & 25 & 24.8 \\
\hline & Male & 53 & 52.5 \\
\hline Specialty & Female & 48 & 47.5 \\
\hline & Hospital medicine & 64 & 63.4 \\
\hline & General internal medicine & 20 & 19.8 \\
\hline Years in clinical practice & Pediatrics & 16 & 15.8 \\
\hline & 9 or less & 60 & 59.4 \\
\hline Children in household & 10 or more & 41 & 40.6 \\
\hline & None & 34 & 33.7 \\
\hline & 1 & 15 & 14.9 \\
\hline Location & 2 or more & 52 & 51.5 \\
\hline & Academic & 74 & 73.3 \\
\hline Volunteered in last 12 months? & Yes & 60 & 25.7 \\
\hline & & & 59.4 \\
\hline
\end{tabular}


Of those who reported professional volunteer activity, 38\% (n=23) volunteered less than 20 hours, $30 \%(n=18) 20-50$ hours, and 32\% ( $n=19)$ more than 50 hours over the last 12 months. Forty-five percent $(n=27)$ volunteered by teaching medical students or medical residents, $43 \%(n=26)$ worked at volunteer medical clinics, 30\% $(n=18)$ participated in organizing regional or national medical conferences, $25 \%(n=15)$ engaged in medical advocacy, and $12 \%(\mathrm{n}=7)$ volunteered on international or domestic medical trips (Table 2). Among those reporting non-professional activity, 27\% spent less than 20 hours, $33 \%$ spent $20-50$ hours, and $40 \%$ spent more than 50 hours in the last 12 months. Table 3 further describes the breakdown of non-professional activity.

Table 2. Time spent volunteering in past 12 months and types of volunteer activities

\begin{tabular}{|l|l|c|c|}
\hline & & $\mathbf{n = 6 0}$ & $\mathbf{\%}$ \\
\hline $\begin{array}{l}\text { Time spent volunteering past 12 } \\
\text { months }\end{array}$ & $<20$ hours & 23 & 38 \\
\hline & $20-50$ hours & 18 & 30 \\
\hline Type of volunteering & $>50$ hours & 19 & 32 \\
\hline & $\begin{array}{l}\text { Teaching medical } \\
\text { students/residents }\end{array}$ & 27 & 45 \\
\hline & Medical clinics & 18 & 43 \\
\hline & Conferences & 15 & 25 \\
\hline & Medical advocacy & 7 & 12 \\
\hline
\end{tabular}

Table 3. Time spent and type of non-professional volunteering in past 12 months

\begin{tabular}{|l|l|l|l|}
\hline & & $\mathrm{n}=61$ & $\%$ \\
\hline $\begin{array}{l}\text { Time spent volunteering } \\
\text { past } 12 \text { months }\end{array}$ & $<20$ hours & 17 & 27 \\
\hline & $20-50$ hours & 20 & 33 \\
\hline & $>50$ hours & 24 & 40 \\
\hline Type of volunteering & School volunteerism & 23 & 38 \\
\hline & Faith based & 18 & 30 \\
\hline & Political advocacy & 16 & 26 \\
\hline & Organizational fundraising & 13 & 21 \\
\hline & Community groups & 13 & 21 \\
\hline & Food distribution & 12 & 20 \\
\hline & Youth sports coaching & 11 & 18 \\
\hline
\end{tabular}


There were no statistically significant differences in the number of hours spent volunteering when comparing hospitalists, general internists and pediatricians (Table 4). Those who were 34 or younger spent fewer hours volunteering in a professional capacity compared with those $35-44$ or 45 or older. Those with 10 or more years of clinical experience, males, those with children were more likely to spend more time in volunteer activity. In both a professional and a non-professional capacity academic physicians spent significantly more hours volunteering.

Table 4. Hours spent volunteering in last 12 months by provider characteristics

\begin{tabular}{|l|l|c|c|c|c|c|}
\hline Characteristic & & $\mathbf{n}$ & $\begin{array}{c}\text { Mean } \\
\text { Hours* }\end{array}$ & $\begin{array}{c}\text { Standard } \\
\text { Deviation }\end{array}$ & t Statistic & p-value \\
\hline $\begin{array}{l}\text { Number of years } \\
\text { in practice }\end{array}$ & 9 or less & 60 & 1.02 & 1.27 & 2.14 & 0.035 \\
\hline & 10 or more & 41 & 1.59 & 1.38 & & \\
\hline Gender & Male & 53 & 1.51 & 1.42 & 2.12 & 0.036 \\
\hline & Female & 48 & 0.96 & 1.18 & & \\
\hline $\begin{array}{l}\text { Children in } \\
\text { household }\end{array}$ & No & 34 & 0.85 & 1.26 & 2.15 & 0.034 \\
\hline & Yes & 67 & 1.45 & 1.34 & & \\
\hline $\begin{array}{l}\text { Professional } \\
\text { capacity }\end{array}$ & Academic & 74 & 1.46 & 1.34 & 2.59 & 0.011 \\
\hline & Community & 26 & 0.69 & 1.19 & & \\
\hline $\begin{array}{l}\text { Non-professional } \\
\text { capacity }\end{array}$ & Academic & 73 & 1.66 & 1.5 & 2.20 & 0.031 \\
\hline & Community & 26 & .92 & 1.35 & & \\
\hline
\end{tabular}

\section{Discussion}

In our survey of five North Carolina hospitals, the majority of providers reported volunteering in a professional capacity within 12 months, most commonly by educating medical students and residents outside of paid duties. There were no statistically significant differences in hours of professional volunteerism among hospitalists, and nonhospitalist internists and pediatricians. Providers who had children in the household, who had more clinical experience, were male and worked at academic hospitals volunteered significantly more hours in a professional and a non-professional capacity than their respective counterparts. Those 34 years or younger showed a trend toward less time volunteering than older providers.

The rate of volunteerism we identified was significantly higher than the $25 \%$ reported in the general population ${ }^{1}$ and among internists performing community volunteering ${ }^{10}$, though was very similar to the volunteerism rate reported in a broader physician survey ${ }^{8}$. 
Similarly, while volunteerism rates in the general population are reported as higher for those with children less than 18 years old ${ }^{1}$, our survey respondents with children reported more volunteer hours. In contrast, the general population survey reported that females volunteered more than males ${ }^{1}$, while our study found the opposite. Physician volunteers likely differ substantially from the population as a whole. For example, professional women may not feel as able to volunteer due to competing demands. Similarly, in the physician population, being older and having children in the household may be markers of financial and career stability that may afford more opportunity to volunteer. We did not survey amount of indebtedness, although one might hypothesize that national trends in increased debt might tend to reduce volunteerism among young professionals.

The finding that academic versus non-academic physicians had a higher rate of volunteerism is interesting. Academic medical centers typically provide practicing physicians with more student and resident contact. This opportunity could lead to selection bias among providers who practice at academic centers toward those who are more active in the community. The mission of the academic hospital where the majority of respondents work includes service to the people of North Carolina. Another possible mechanism is the increased size of academic centers, which could afford greater opportunity to volunteer more easily.

Limitations of our study include the self-reported nature of the data and relatively low survey response rate from community physicians. Those who completed the survey may have had more interest in volunteering as opposed to those who did not, thus introducing bias. In addition, self-reported responses are subject to recall bias. These limitations are balanced against the strengths of multi-center and multi-specialty participation.

In summary, our study reports characteristics of physician professional volunteerism from five North Carolina hospitals, with emphasis on providers in hospital medicine, a relatively new specialty. Understanding these trends will be helpful to guide and mentor residents and early career faculty, particularly those with an interest in community service, and to guide conversation on how to encourage this valuable service. We hope these data can also open conversation regarding volunteerism as a means of professional and faculty development. In addition, further study is warranted regarding women in medicine, career and family life balance, and indebtedness.

\section{Notes}

Author contributions: All authors have seen and approved the manuscript, and contributed significantly to the work.

Financial support: Authors declare that no financial assistance was taken from any source.

Potential conflicts of interest: Authors declare no conflicts of interest.

\section{References}

1. Bureau of Labor Statistics. Volunteering in the United States - 2013. http://www.bls.gov/news.release/volun.nr0.htm. Accessed February 14, 2015.

2. Thoits PA, Hewitt LN. Volunteer work and well-being. J Health Soc Behav. 2001;42(2):115-131.

3. Schwartz C, Meisenhelder JB, Ma Y, Reed G. Altruistic social interest behaviors are associated with better mental health. Psychosom Med. 2003;65(5):778-785. 
4. Sneed RS, Cohen S. A prospective study of volunteerism and hypertension risk in older adults. Psychol Aging. 2013;28(2):578-586.

5. Oman D, Thoresen CE, McMahon K. Volunteerism and Mortality among the Communitydwelling Elderly. J Health Psychol. 1999;4(3):301-316.

6. Musick MA, Herzog AR, House JS. Volunteering and mortality among older adults: findings from a national sample. J Gerontol B Psychol Sci Soc Sci. 1999;54(3):S173-180.

7. Brown SL, Nesse RM, Vinokur AD, Smith DM. Providing social support may be more beneficial than receiving it: results from a prospective study of mortality. Psychol Sci. 2003;14(4):320-327.

8. Medscape Physician Lifestyle Report 2012.

http://www.medscape.com/features/slideshow/lifestyle/2012/public. Accessed February 14, 2015.

9. Eliason BC, Guse C, Gottlieb MS. Personal values of family physicians, practice satisfaction, and service to the underserved. Arch Fam Med. 2000;9(3):228-232.

10. Grande D, Armstrong K. Community volunteerism of US physicians. Journal of General Internal Medicine. 2008;23(12):1987-1991.

11. Ambiee JP. Examining physician's motivations to volunteer: An applied visual anthropological approach. 2007; http://scholarcommons.usf.edu/etd/601/. Accessed February 14, 2014. 


\section{Appendix - Survey}

1. How old are you $<30,30-34,35-39,40-44,45-50,>50$

2. Sex Male Female

3. Professional Title MD/DO, NP, PA Other (please specify)

4. Where do you practice? Duke University Medical Center Duke Regional Hospital Duke Raleigh

Hospital Rex Healthcare UNC Hospitals WakeMed Health \& Hospitals Durham VA Medical Center

5. Specialty/area of focus: Internal Medicine Hospital Medicine Program, General Internal Medicine,

Internal Medicine/Pediatrics Hospital Medicine Program, Internal Medicine/Pediatrics, Pediatrics, Hospital

Medicine Program Pediatrics

6. Number of years in clinical practice, not including residency/training: 0-4, 5-9, 10-14,15-20, > 20

7. Number of children ( $<18$ years old) in your household $0,1,2-3,>3$

8. Average number of hours spent in clinical work per week since 7/1/2012 <10, 10-20, 21-30, 31-40, 41-

$50,>50$

9. Since July 1 st of 2012, have you participated in any volunteer activities? Yes No

10. What type(s) of PROFESSIONAL volunteer work have you done since 7/1/2012? Check all that apply. (Professional volunteer work includes unpaid activities in which you primarily use your skills as a medical doctor or healthcare provider.)

Medical student/resident teaching outside of normal working hours, Volunteer medical clinics,

International/domestic medical trips, Medical advocacy (speaking engagements, political groups, etc.),

Regional or national professional group involvement

Other (please specify)

11. Since 7/1/2012, on how many separate days have you volunteered in a PROFESSIONAL capacity? $<5$, $5-9,10-14,15-20,>20$

12. Since 7/1/2012, approximately how many hours have you volunteered in a PROFESSIONAL capacity $<20$,

$20-50,51-80,>80$

13. What type(s) of NON-PROFESSIONAL volunteer work have you done since 7/1/2012? Check all that apply. (NON-PROFESSIONAL volunteer work includes unpaid activities in which you do NOT primarily use your skills as a medical doctor or healthcare provider.)

School volunteerism ,Youth sports coaching, Nursing home volunteerism, Organizational fundraising, Faith-based volunteerism (ex: be an usher, greeter or minister), Political advocacy, Collect, prepare, distribute or serve food, Homeowners associations, event organizations, other community groups Other (please specify)

14. Since $7 / 1 / 2012$, on how many separate days have you volunteered in a NON-PROFESSIONAL capacity?

$<5,5-9,10-14,15-20,>20$

15. Since 7/1/2012, approximately how many hours have you volunteered in a NON-PROFESSIONAL capacity?

$<20,20-50,51-80,>80$

16. How did you initially become involved in your volunteer activities? Check all that apply. Asked to participate by work colleague, Asked to participate by friend, Independently sought out opportunity, Initial work was obligatory but continued on as volunteer, Other (please specify)

17. How often do work commitments limit the amount of volunteer work that you do? Always, Sometimes, Rarely, Never

18. How often do family commitments limit the amount of volunteer work that you do? Always, Sometimes, Rarely, Never

19. How often does lack of time for other reasons limit the amount of volunteer work that you do? Always, Sometimes, Rarely, Never

20. How often do financial concerns (ex. student debt, mortgage, etc) limit the amount of volunteer work that you do? Always, Sometimes, Rarely, Never

21. How often does a lack of financial incentive to volunteer limit the amount of volunteer work that you do? Always, Sometimes, Rarely, Never

22. How often do malpractice/litigation concerns limit the amount of volunteer work that you do? Always, 
Sometimes, Rarely, Never

23. How often does the feeling that your primary occupation is significant community service limit the amount of volunteer work that you do?

Always, Sometimes, Rarely, Never

24. What else prevents you from doing more volunteer work? Please briefly describe.

25. Overall satisfaction with your current job? Extremely satisfied, Satisfied, Neutral, Unsatisfied,

Extremely unsatisfied 